\title{
Effect of Step Quenching Heat Treatments on the Kinetics of Ferrite Formation and Quenching \& Partitioning Modeling for a Commercial C-Mn-Si Steel
}

\author{
Charles H. X. M. Magalhães ${ }^{l *}$ (1), Pablo H. K. Campos ${ }^{l}$, Geraldo L. Faria ${ }^{l}$ () \\ ${ }^{1}$ Universidade Federal de Ouro Preto, 35400-000, Ouro Preto, MG, Brasil.
}

Received: May 28, 2021; Revised: October 01, 2021; Accepted: October 08, 2021.

\begin{abstract}
Aiming to meet current demands from the automotive industry, a third generation of advanced high strength steel (AHSS) has been developed as an alternative to previous generations. Different alloys and innovative processes have been deeply studied as, for example, quenching and partitioning (Q\&P). The published papers highlight that the best heat treatment parameters for a satisfactory Q\&P execution are strongly dependent on the austenite conditioning and they can be optimized if thermodynamic and kinetics calculations are performed. In this context, this work evaluated the effect of step quenching (SQ) heat treatments on the kinetics of ferrite formation and Q\&P modeling for a commercial C-Mn-Si steel, predicting the microstructural evolution and the final phase fractions as a function of the heat treatment parameters. The JMAK model was optimally fitted to the ferrite fraction, as well as to the microhardness data. The kinetics characterization and the thermodynamic modeling showed that the combination of SQ and Q\&P can provide a high retained austenite fraction in a multiphase microstructure. As a conclusion, it is possible to state that a well-planned SQ heat treatment followed by an optimized Q\&P cycle has the potential to generate an advanced steel with a final microstructure assisted by the TRIP effect.
\end{abstract}

Keywords: Step quenching, kinetics of ferrite formation, quenching and partitioning modeling, AHSS, thermodynamics simulation.

\section{Introduction}

New global standards of vehicle safety, fuel economy, and gas emission limitations have already been established in several countries to the present date, with increasingly strict targets being proposed for the coming decades. Thus, the automotive industry often seeks the development of advanced designs and materials that are economically viable, manageable, and capable of meeting the required environmental and safety requirements. Therefore, a program to develop a new vehicle must balance safety, performance, fuel economy, environmental sustainability, and a consumer interest design ${ }^{1-4}$.

In this context, the decrease of car body weight has been proposed in order to increase energy efficiency and to reduce gas emissions, as well as to rise impact resistance seeking to guarantee the vehicle occupant safety. These efforts led to a quickly increased demand for advanced high strength steel (AHSS) sheets with good mechanical formability ${ }^{5-7}$. The first AHSS generation, to which the Dual Phase steels (DP) and Transformation Induced Plasticity (TRIP) belongs, is still widely used in the manufacture of vehicle's body in white (BIW) due to the good provided combination of mechanical resistance and ductility. To obtain these steels, intercritical annealing heat treatments are usually applied during the alloy processing.

An alternative to this type of heat treatment is the Step Quenching (SQ). It consists of a steel complete austenitizing

*e-mail: charlesmagalhaesop@gmail.com. followed by an intercritical annealing and final quenching. The SQ heat treatment eliminates a process step in relation to the conventional intercritical austenitizing heat treatment. When the intercritical austenitizing is used aiming to obtain a AHSS for automotive industry, usually, it is performed with an initial complete austenitizing followed by quenching and, just after this, an intercritical austenitizing followed by quenching is executed ${ }^{8}$. Both described strategies are used with the aim to obtain a well-conditioned austenite grains, richer in carbon and with small grain size, allowing the achievement of high mechanical strength and good formability in the processed steel ${ }^{9,10}$. These steels have complex and often multiphase structures, containing ferrite, bainite, martensite and retained austenite, depending on the thermomechanical cycles to which they are subjected. The constituents of this complex structure can offer good properties to the alloy such as high mechanical strength, due to the martensite contribution, and good ductility, due to the ferrite contribution. In the case of TRIP steels, it is possible to increase the mechanical strength without significant loss of ductility and toughness due to the bainite and retained austenite contributions $\mathrm{s}^{3,11}$.

Shao et al. ${ }^{12}$, studying a high mechanical strength and low alloy steel (HSLA), concluded that a favorable balance of mechanical properties can be obtained through the wellplanned application of advanced heat treatments such as Step Quenching (SQ). After the complete austenitizing, the SQ treatment consists of subjecting the steel to a controlled 
cooling aiming to promote the austenite supercooling up to a desired temperature. At this temperature, it will be isothermally treated to provide a partial austenite to ferrite decomposition. The isothermal treatment is performed at a strategically chosen temperature and during a well-planned time interval, in order to obtain the desired ferrite and austenite fractions. Next, the steel is cooled at high enough rate to promote the transformation of a part of the remaining austenite into martensite, maintaining a fraction of austenite, enriched in carbon, retained in the microstructure ${ }^{13,14}$. Some authors have reinforced that for the successful fine-tuning of the microstructure and the precise control of mechanical properties, it is necessary to understand and to predict the kinetics of ferrite formation in SQ cycles ${ }^{12-14}$.

Some studies have even shown that quenching and partitioning (Q\&P) heat treatments applied to some steels with initial ferrite-austenite microstructure, aiming to develop the third generation of AHSS, can be greatly efficient. This initial structure can be obtained by the use of SQ heat treatments performed prior to the Q\&P cycles $^{6,15,16}$. Originally, the Q\&P concept was proposed by Speer et al. ${ }^{17}$ as a promising process in order to produce a steel with superior mechanical properties compared to the first generation of AHSS. Initially, the Q\&P heat treatment was developed for steels with chemical compositions similar to those of TRIP and carbide-free bainitic steels (CFB). The main goal of the Q\&P process is to control the amount and stability of retained austenite in the microstructure, in order to form microstructures that provide greater material toughness, by means of the carbon partition from martensite to untransformed austenite, at temperatures between $\mathrm{M}_{\mathrm{s}}$ (martensite start temperature) and $\mathrm{M}_{\mathrm{f}}$ (martensite end temperature), or slightly higher than $\mathrm{M}_{\mathrm{s}}$.

According to Dai et al. ${ }^{4}$, during a $\mathrm{Q} \& \mathrm{P}$ process, the final microstructure can be achieved by applying different route processes which involves de correct definition of several heat treatment parameters. For a specific steel, the success of the Q\&P heat treatment depends on the austenite conditioning (austenitizing type, phase fraction, chemical composition and grain size), as well as heating and cooling rates, quenching temperature, partitioning temperature, occurrence of carbide precipitation, partitioning time, thermomechanical processing, etc. This leads many authors to propose different processes (e.g.: stepping-quenching and partitioning (S-Q\&P), quenching-partitioning-tempering (Q\&P-T), quenching-tempering and partitioning (Q-T\&P) and quenching and flash-partitioning $(\mathrm{QFP}))^{18-21}$ involving the concept of Q\&P. Thus, different alloys ${ }^{22}$ have been studied and submitted to processes similar to those above mentioned, seeking to favor a higher retained austenite fraction in the final microstructure and, consequently, resulting in a steel with superior mechanical properties.

Therefore, the design of a Q\&P process involves the metallurgical and process parameters optimization, such as austenite conditioning, carbide precipitation kinetics, fraction of formed martensite, kinetics of carbon partition, retained austenite morphology and stabilization, bainitic transformation during partitioning, among others. The wellunderstand of these metallurgical phenomena is highly important, because its effects on the Q\&P heat treatment will determine the steel final microstructure and mechanical properties. In this scenario, the kinetic and thermodynamic simulations are essential in order to determine optimized heat treatment parameters. Thus, thermodynamic and/or kinetic models have been proposed ${ }^{4,23}$ in order to simplify process variables and to obtain a reasonable prediction about the final microstructure and mechanical properties of Q\&P steels.

In this context, this work proposed to evaluate the effect of SQ heat treatment on ferrite formation kinetics and microstructural evolution of a commercial C-Mn-Si steel with typical chemical composition of a TRIP780. By means of physical simulations performed in a quenching dilatometer, the effect of three step temperatures on the ferrite fraction formed in a quasi-equilibrium condition was evaluated. For a specific temperature where the operational control of the ferrite fraction was more efficient, the kinetics of its formation was characterized applying Johnson-MehlAvrami-Kolmogorov model (JMAK). Moreover, the kinetics of ferritic grain growth as a time function was modeled by the Zener's law (1949) ${ }^{24}$. Using the MatCalc software and thermodynamic models ${ }^{17,25}$ applied to the quenching and partitioning concept, Q\&P cycles considering previous SQ heat treatments (SQ-Q\&P) were thermodynamically simulated and the final phase fractions were predicted for optimized heat treatment conditions.

The modeling and optimizing of the SQ-Q\&P heat cycles applied to the TRIP 780 commercial steel type are unprecedented and of great relevance for the industry and researchers looking for alternatives to develop commercially viable third generation AHSS steels.

\section{Materials and Methods}

The material studied in this work was a C-Mn-Si steel with the typical chemical composition of a TRIP780 commercial steel for automotive application (Table 1). The sampling procedure was carried out at an intermediate hot rolling process stage with a plate thickness of $4 \mathrm{~mm}$, presenting an initial microstructure constituted of proeutectoid ferrite and pearlite (Figure 1), not presenting, hence, a typical structure of a finished TRIP steel.

The microhardness in the as-received condition was measured on a Vickers scale using the Pantec microhardness machine, model HXD 1000TM. The applied load was 300gf for 5 seconds. The average microhardness value was calculated from fifteen random aleatory measurements performed in the sample. Its value was $(233 \pm 5) \mathrm{HV}$.

The physical simulations to evaluate the effect of step temperatures on the ferrite fraction on the quasi-equilibrium condition were performed in a Linseis R.I.T.A. L78 quenching dilatometer. For this purpose, it was necessary to machine

Table 1. Studied steel chemical composition (wt.\%).

\begin{tabular}{cccccccccc}
\hline $\mathrm{C}$ & $\mathrm{Mn}$ & $\mathrm{Si}$ & $\mathrm{P}$ & $\mathrm{S}$ & $\mathrm{Cr}$ & $\mathrm{Cu}$ \\
\hline 0.23 & 1.63 & 1.32 & 0.0257 & 0.0014 & 0.03 & 0.02 & 0.02 & \\
\hline
\end{tabular}


Table 2. SQ heat treatment routes employed to evaluate the step temperature effect on ferrite fraction on the quasi-equilibrium condition.

\begin{tabular}{cccc}
\hline Step Temperature $\left({ }^{\circ} \mathrm{C}\right)$ & Cooling rate before Step $\left({ }^{\circ} \mathrm{C} / \mathrm{s}\right)$ & Step Time $(\mathrm{s})$ & Cooling rate after Step $\left({ }^{\circ} \mathrm{C} \mathrm{s}^{-1}\right)$ \\
\hline 800 & 15 & 600 & 200 \\
\hline 750 & 15 & 600 & 200 \\
\hline 700 & 15 & 600 & 200 \\
\hline
\end{tabular}

Table 3. SQ heat treatment routes used to characterize the kinetics of ferrite formation at T $\alpha$ temperature.

\begin{tabular}{cccc}
\hline Step Temperature $\left({ }^{\circ} \mathrm{C}\right)$ & Cooling rate before Step $\left({ }^{\circ} \mathrm{Cs}^{-1}\right)$ & Step Time $(\mathrm{s})$ & Cooling rate after Step $\left({ }^{\circ} \mathrm{Cs}^{-1}\right)$ \\
\hline $\mathrm{T} \alpha$ & 15 & 5 & 200 \\
\hline $\mathrm{T} \alpha$ & 15 & 10 & 200 \\
\hline $\mathrm{T} \alpha$ & 15 & 15 & 200 \\
\hline $\mathrm{T} \alpha$ & 15 & 30 & 200 \\
\hline $\mathrm{T} \alpha$ & 15 & 60 & 200 \\
\hline $\mathrm{T} \alpha$ & 15 & 600 & 200 \\
\hline $\mathrm{T} \alpha$ & 15 & 1200 & 200 \\
\hline
\end{tabular}

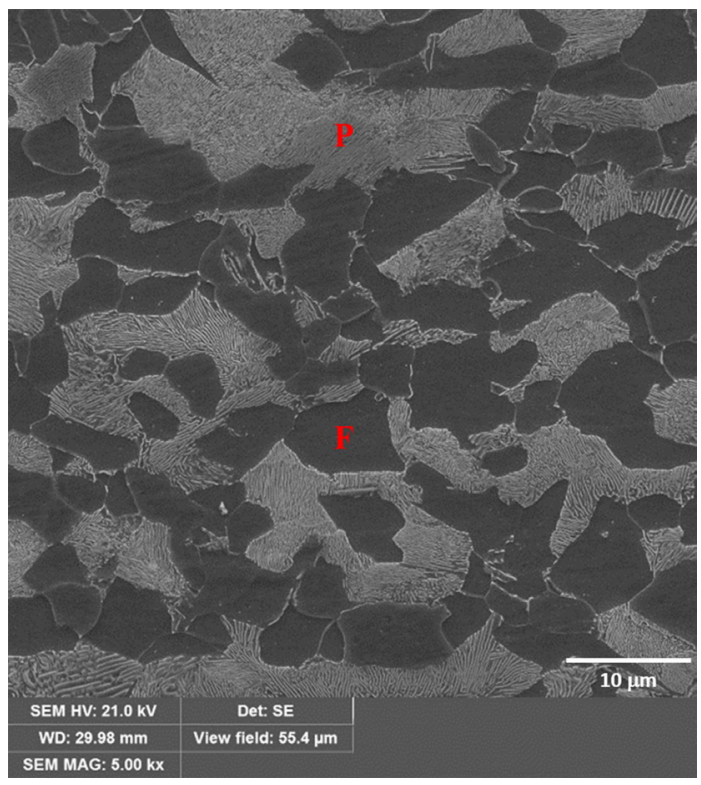

Figure 1. Studied steel microstructure in its as-received condition. F: Ferrite; P: perlite - SEM-5000x - 4\% Nital etching.

solid dilatometry specimens with cylindrical geometry $(10 \mathrm{~mm}$ in height $\mathrm{x} 3 \mathrm{~mm}$ in diameter). These specimens were sampled with their height aligned with the plate hot rolling direction. Based on the CCT diagram determined for the studied steel in a previous study ${ }^{11}$, three SQ heat treatment routes (Table 2 ) were initially proposed to verify the influence of step temperatures on the microstructure, ferrite fraction, and microhardness.

It should be noted that: a) the used austenitizing conditions were the same as those employed by Magalhães et al. ${ }^{11}$, i.e., $950^{\circ} \mathrm{C}$ for 3 minutes; $b$ ) the specimen cooling rate starting from its austenitizing condition to step temperature, $15^{\circ} \mathrm{Cs}^{-1}$, were selected as being the lowest possible rate that would guarantee, for the three evaluated step temperatures, that the austenite decomposition in ferrite would only start during isotherm and not during continuous cooling ${ }^{11}$; c) the time interval of 10 minutes was selected to give sufficient time for a quasi-equilibrium state to be achieved, which was successful in terms of the formed ferrite fraction, as it will be presented and discussed in the results ${ }^{14} ;$ d) the cooling rate of $200^{\circ} \mathrm{C}$ $\mathrm{s}^{-1}$ was defined as a cooling rate at which the non-occurrence of bainitic transformation was guaranteed during the final specimen cooling, and the final microstructures consisted of different ferrite, martensite, and retained austenite fractions ${ }^{11}$.

After performing heat cycles, the dilatometry specimens were cut in half. The specimen cross sections were metallographically prepared following the standardized procedures recommended by the ASTM E ${ }^{26}$. The specimens were etched with Nital $4 \%$ and the image acquisition was performed in a Leica DM2700M optical microscope (OM).

The ferrite fraction was measured in each specimen by using the automatic area method of quantitative metallography, recommended by ASTM E1245 27 . To improve contrast and increase the efficiency of the used method, the specimens were again etched with Picral 5\%. In each specimen, thirteen images were acquired with a magnification of 200x to measure the average ferrite volumetric fraction. Vickers microhardness tests were also performed on all treated specimens, using a Pantec microhardness machine, model HXD 1000TM. The applied load was $300 \mathrm{gf}$ for a 5 seconds time interval. The average microhardness values of each specimen were obtained by calculating the arithmetic average from 15 measurements randomly sampled on the specimen cross-section.

Based on the results obtained in the previous step, the most favorable step temperature $\left(\mathrm{T}_{\alpha}\right)$ was defined for the best control of ferritic phase fraction. For this temperature, seven other heat treatment routes were proposed (Table 3) to verify the influence of step time on the formed ferrite fraction, ferritic grain growth and on the microhardness of the transformation products. All heat treatments were simulated in a quenching dilatometer, with specimens and austenitizing conditions identical to those already described.

The specimens of this stage have undergone the same microstructural characterization procedures, ferrite fraction measurement, and Vickers microhardness measurement, as already previously described. 
All specimens generated at this study stage had ferritic grain sizes measured by applying the intercept method according to the ASTM E112 standard $^{28}$. To highlight the grain boundaries and to increase the method efficiency, the specimens were metallographically prepared and etched in the following sequence: Nital $4 \%$ for 5 seconds, followed by an etching with a reactive consisting of $1 \mathrm{~g}$ of sodium metabisulfite and $100 \mathrm{ml}$ of distilled water, for 8 seconds. For each specimen, 5 images with a magnification of 500x were acquired and, in each image, 10 test lines were applied to count the intercepts with the ferritic grain boundaries, totaling 50 lines for each specimen.

To evaluate the kinetics of ferrite formation at $T_{\alpha}$ temperature, the JMAK equation was fitted to the experimental data. The JMAK model shows that for isothermal phase transformations, the fraction of the new formed phase can be predicted as a function of time as Equation 1 presents, where $x$ is the new phase fraction, $k$ is the temperature-dependent kinetic constant, $n$ is the Avrami exponent, and $t$ is time th,29,30. $^{14}$.

$x=1-\exp \left(-k t^{n}\right)$

In the same way that the ferrite fraction was measured as a function of step time for the temperature $T_{\alpha}$, the Vickers microhardness was also measured and, considering the relationship of microhardness variation with the phase fraction changes in the microstructure, the so-called softening factor (SF) was calculated. As a result, the JMAK model was also fitted to the obtained data. The SF can be predicted as a time function applying Equation 2, where $S F$ is the softening factor, $H V_{\max }$ is the maximum hardness obtained in the just as quenched specimen (majorly martensitic), $H V_{\text {min }}$ is the minimum hardness obtained in the specimen with ferrite fraction in the quasi-equilibrium condition (highest ferrite fraction) and $H V_{t}$ is the hardness obtained in the SQ at any time interval ${ }^{14}$.

$$
S F=\frac{H V_{\text {máx }}-H V_{t}}{H V_{\text {máx }}-H V_{\text {min }}}=1-\exp \left(-k t^{n}\right)
$$

To evaluate the kinetics of ferritic grain growth, Zener's equation ${ }^{24}$ was fitted to the data obtained in the measurement of ferritic grain sizes for different step time intervals at the temperature $\mathrm{T}_{\alpha}$. Zener's equation ${ }^{24}$ shows that the ferritic grain size can be predicted as a time function according to Equation 3, where $D$ is the allotriomorph ferritic size, $\alpha$ is a proportionality constant that is a function of the transformation temperature and steel chemical composition, and $t$ is the time.

$$
D=\alpha \sqrt{t}
$$

The $\mathrm{M}_{\mathrm{s}}$ temperatures were experimentally determined from the dilatometric data. The samples isothermally heat treated at $\mathrm{T}_{\alpha}$ for different time intervals were all them quenched. The relative length versus temperature curves, for each one of them, were mathematically treated and de
$\mathrm{M}_{\mathrm{s}}$ temperatures were determined as a step time function observing the minimum deviation method ${ }^{31}$.

Aiming to simulate and to calculate the optimized parameters for SQ-Q\&P (step quenching combined with quenching and partitioning heat treatments) for the studied steel, thermodynamic simulations were performed using: the MatCalc software, provided with the $m c$ fe 2.060 database; the CCE model, proposed by Speer et al. ${ }^{17}$; and CCET model, proposed by Li et al. ${ }^{25}$. For the CCET model to be used, considering the chemical composition of studied alloy, the $\mathrm{T}_{0}$ curve $^{32}$ was raised in the MatCalc software. The obtained data was mathematically treated using the OriginPro 9.0 software.

In a summarized way, the Koistinen-Marburger (K-M) equation was used to determine the martensite and austenite fractions after partial quenching in a Q\&P cycle. According to the $\mathrm{CCE}$ mode ${ }^{17}$, from the relationship between carbon activities in $\alpha$ and $\gamma$ phases, the carbon molar fractions in these phases can be determined for a given temperature and chemical composition, and in turn, the carbon content of the untransformed austenite (from partial quenching) after the partitioning stage can be known. Again, by the K-M equation, the final retained austenite fraction was determined after final quenching. In addition to this, the CCET model ${ }^{25}$ considers $^{2}$ the decomposition of the untransformed austenite into bainite (without carbide precipitation) according to the $\mathrm{T}_{0}$ curve $^{32}$, during the partitioning stage. Hence, it was possible to predict the martensite, bainite and retained austenite fractions in the final microstructure.

\section{Results and Discussion}

\subsection{Effect of the step temperature on the ferrite fraction in quasi-equilibrium condition}

The step temperatures studied in this work were $800^{\circ} \mathrm{C}$, $750^{\circ} \mathrm{C}$, and $700^{\circ} \mathrm{C}$. For the specimen submitted to the highest step temperature $\left(800^{\circ} \mathrm{C}\right.$ ) (Figure $2 \mathrm{~A}$ ), considering the studied steel CCT diagram ${ }^{11}$, ferrite formation was expected to occur. However, this was not observed in the OM images. Considering the applied cooling rate of $15^{\circ} \mathrm{Cs}^{-1}$ and the relatively high step temperature, this occurred probably due to an insufficient driving force for ferrite nucleation and growth. Ashrafi et al. ${ }^{14}$, studying a DP steel, observed a similar effect. According to them, for the same step time intervals, the higher the isotherm temperature, the lower the ferrite fraction. In addition, the authors showed that at the highest step temperature $\left(780^{\circ} \mathrm{C}\right)$, even applying the highest step time (50 seconds), the measured ferrite fraction was lower than the verified for lower temperatures and shorter step times: $750^{\circ} \mathrm{C}$ for 30 seconds and $720^{\circ} \mathrm{C}$ for 10 seconds $^{14}$.

In the specimens submitted to steps at $750^{\circ} \mathrm{C}$ and $700^{\circ} \mathrm{C}$, ferrite formation was significant, and could be identified by $\mathrm{OM}$. This happened probably due to the austenite supercooling increase and, consequently, the higher driving force for transformation, favoring the kinetics of austenite to ferrite transformation. Figure 2 compares the microstructures of heat-treated specimens at $800^{\circ} \mathrm{C}, 750^{\circ} \mathrm{C}$ and $700^{\circ} \mathrm{C}$ for $600 \mathrm{~s}$. Comparing the specimens treated at $800^{\circ} \mathrm{C}$ and $700^{\circ} \mathrm{C}$ (Figure 2-A and Figure 2-C), there is a significant 
microstructure change. Increasing only $100^{\circ} \mathrm{C}$ in the austenite supercooling, there is a notable spike in the formed ferrite fraction. Comparing the specimens submitted to $750^{\circ} \mathrm{C}$ and $700^{\circ} \mathrm{C}$ (Figure 2-B and Figure 2-C), a significant increase in ferrite fraction is again noticed with a $50^{\circ} \mathrm{C}$ increase in austenite supercooling.

This obtained results means that the ferrite fraction in TRIP780 steel, rich in Mn, a gamagenic element, is strongly sensitive to the austenite supercooling degree in the SQ heat treatments. In this scenario, $700^{\circ} \mathrm{C}$ (called $\mathrm{T} \alpha$ in this work) can be affirmed to be the most favorable temperature, among those studied, for the operational control of the ferrite growth in TRIP780 steel.

Figure 3 shows the ferrite volumetric fractions, as well as the specimen microhardness values as a function of the studied step temperatures. It is noticed that the highest ferrite fraction was $31 \%$ for $700^{\circ} \mathrm{C}$ step temperature. It is also noticed that, with the ferrite fraction increase, there is a significant decrease in steel hardness. While the specimen submitted to $800^{\circ} \mathrm{C}$, with microstructure mostly martensitic,

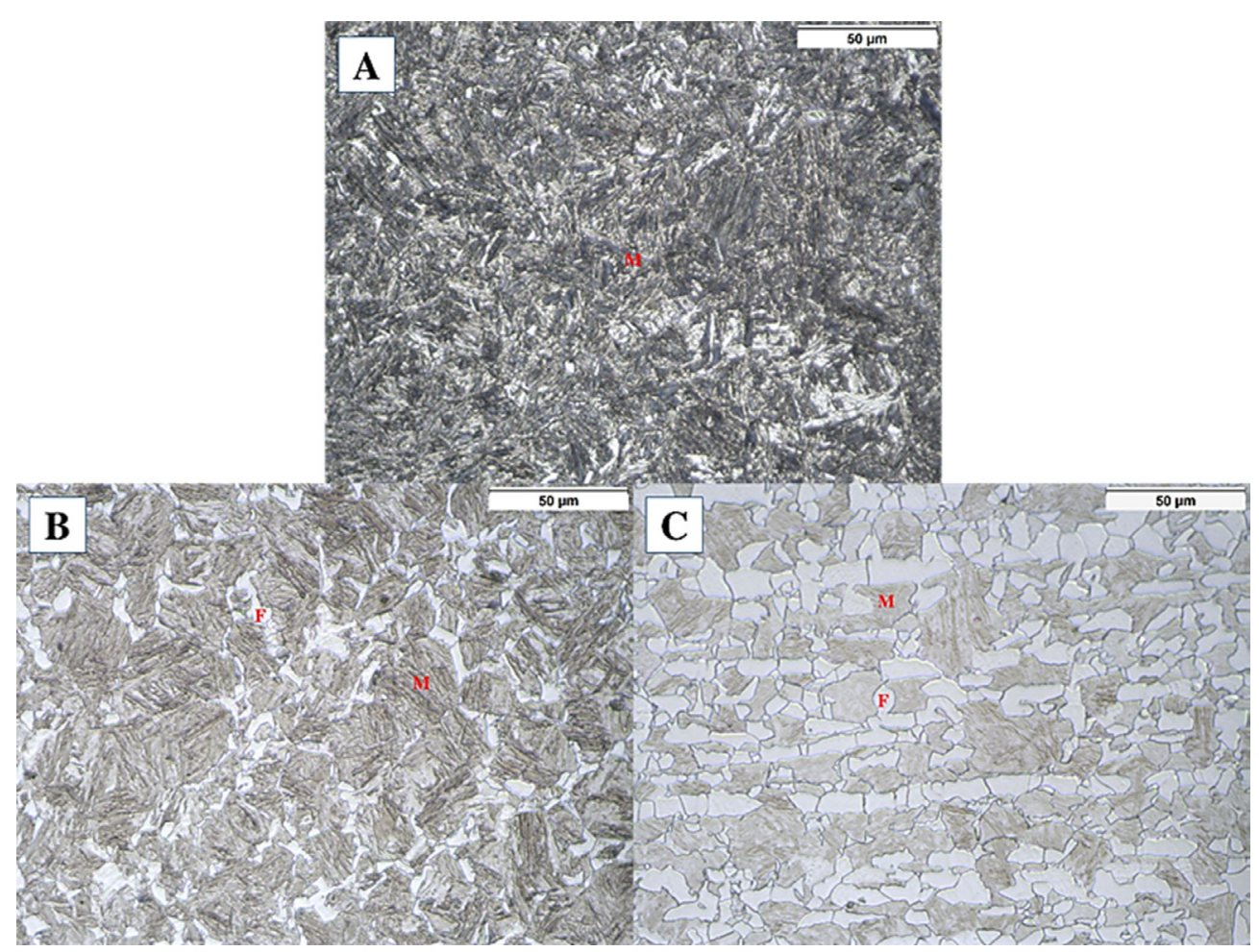

Figure 2. Microstructures of TRIP780 steel specimens submitted to Step Quenching heat treatment in isotherms: A) $800^{\circ} \mathrm{C}$; B) $750^{\circ} \mathrm{C}$; C) $700^{\circ} \mathrm{C}$. F: Ferrite; M: Martensite - OM-500x - 4\% Nital etching.

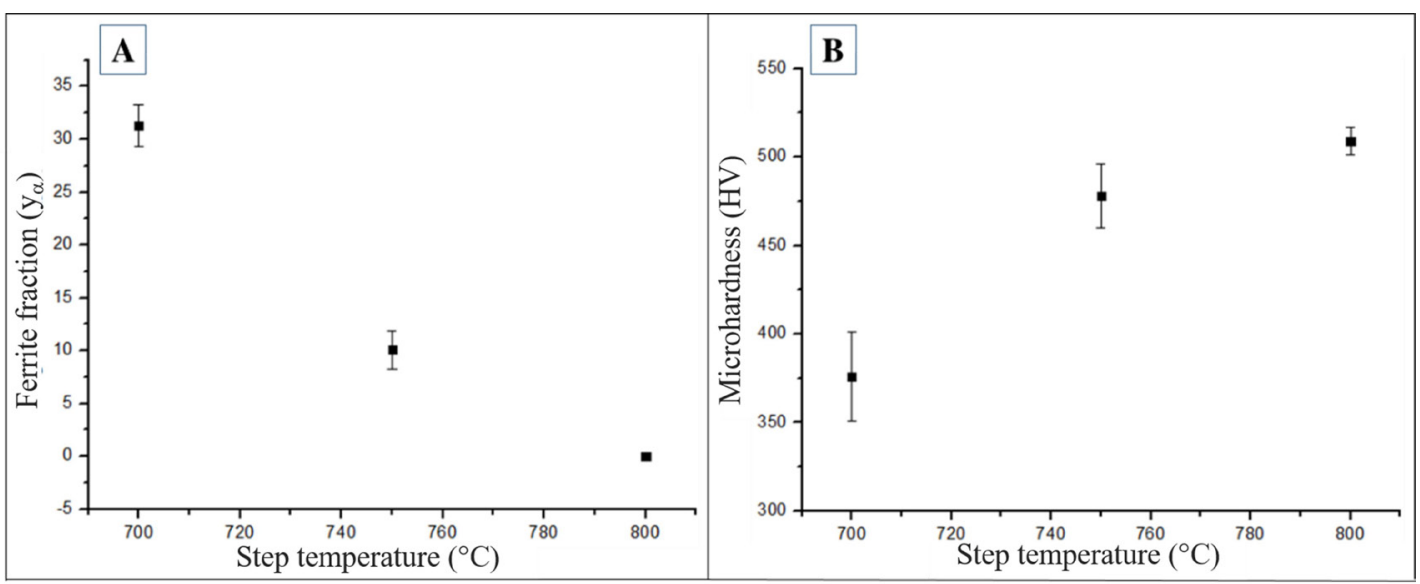

Figure 3. A) Ferrite fraction $\left(\mathrm{y}_{\alpha}\right)$ as a function of step temperature in the quasi-equilibrium and B) vickers microhardness (HV) as a function of step temperature. 
has $509 \mathrm{HV}$, the specimen with $31 \%$ of ferrite has $376 \mathrm{HV}$, representing a $26 \%$ decrease.

\subsection{Characterization of the ferrite formation kinetics at step temperature of $700^{\circ} \mathrm{C}$}

As shown in the previous topic, the most favorable step temperature for ferrite fraction control was $700^{\circ} \mathrm{C}$. Due to this finding, tests were performed to verify the effect of step time on the ferrite fraction and grain size. As previously described in Materials and Methods section, each specimen was maintained in this isotherm by different time intervals, which were $5 \mathrm{~s}, 10 \mathrm{~s}, 30 \mathrm{~s}, 60 \mathrm{~s}, 600 \mathrm{~s}$, and $1200 \mathrm{~s}$, and were subsequently cooled at $200^{\circ} \mathrm{Cs}^{-1}$ to room temperature. Figure 4 shows the microstructures of the specimens submitted to these conditions. Figures 5-A and 5-B show the ferrite fraction and the specimen microhardness values as a function of step time, respectively. It can be observed that there was an increase in ferrite fraction with the increase of the step time interval, which was expected, due to the longer time for carbon diffusion in the crystalline bulk. As it is well known, the kinetics of ferrite formation is controlled by the carbon diffusion in austenite and, if the diffusion is more effective, it will favor the displacement of the ferrite-austenite phase boundaries. As diffusion is a thermally activated process and evolves over time, this behavior was expected ${ }^{33}$.

In the specimens kept at the step temperature for the longest time intervals (10 min. and $20 \mathrm{~min}$.), it was possible to observe similar ferrite fractions, as illustrated by Figure 4-F and Figure 4-G, which was expected. This occurred because, as previously mentioned, the time intervals greater than $10 \mathrm{~min}$. were selected to provide a quasi-equilibrium state, i.e. the maximum possible ferrite fraction was formed for this experimental condition. Figure 5-A highlights that after 60 s at the isotherm, the ferrite fraction already approaches asymptotically the equilibrium fraction. A similar observation was also made by Ashrafi et al. ${ }^{14}$, which showed that when a DP steel is subjected to an isotherm at $720^{\circ} \mathrm{C}$, from $100 \mathrm{~s}$ on, the ferrite fraction already approaches asymptotically to the equilibrium fraction ${ }^{14}$.

Considering that the ferrite fraction and the Vickers microhardness were experimentally determined as a time function for the $700^{\circ} \mathrm{C}$ step temperature $\left(\mathrm{T}_{\alpha}\right)$ (Figures 5-A and Figure 5-B), it was possible to fit the JMAK model to the experimental data measured for the TRIP780 steel. The JMAK equation was fitted to the ferrite fraction data in its usual form (Equation 1) as well as it was fitted to the microhardness data in its SF form (Equation 2).

The JMAK model is widely used to evaluate the kinetics of diffusional phase transformations, so it can be used to predict the temporal evolution of the ferrite fraction. Modeling the kinetics of ferritic phase transformation is essential for the efficient planning of a SQ heat treatment to be applied in a specific steel ${ }^{14,29,30}$.

The JMAK model provides the formation of $100 \%$ of the interest phase $(y=1)$ for times that tend towards infinity. However, for TRIP780 steel, at $700^{\circ} \mathrm{C}$, the ferrite fraction reaches a maximum and constant value $\left(\mathrm{y}_{\mathrm{e}}=0,38\right)$ from a certain time interval. That would be the ferrite fraction in the quasi-equilibrium. In this case, it can be considered that the instantaneous ferrite fraction $\left(y_{\alpha}\right)$ for a long time interval will tend towards this maximum quasi-equilibrium fraction $\left(y_{e}\right)$. In this scenario, it can be written that $y_{\alpha} / y_{e}=1$. Thus, the classic JMAK equation could be adapted to the form presented in Equation 4. Thus, aiming to achieve good predictability about the ferrite formation kinetics, it was necessary to fit the Equation 4 to the experimentally determined data and, consequently, to determine the fitting constants $\mathrm{k}$ and $\mathrm{n}$ for the studied steel.

$\frac{y_{\alpha}}{y_{e}}=1-\exp \left(-k t^{n}\right)$

Fitting Equation 4 to the experimental data, the Avrami exponent $(n)$ was determined as $1.5 \pm 0.2$ and the kinetic temperature-dependent constant $(k)$ as $(6 \pm 3) \times 10^{-3}$. The correlation coefficient was $R^{2}=0.99$, as shown in Figure 6-A. This shows that the kinetics of ferrite formation, in the SQ heat treatments at $700^{\circ} \mathrm{C}$, follow the JMAK model for the studied steel. According to the literature, for isothermal phase transformations, as the studied ferritic transformation, when the Avrami exponent is between 1 and 2, this means that the nucleation of the new formed phase occurs heterogeneously in preferential sites which are the austenitic grain boundaries after local saturation ${ }^{34}$. This observation is consistent with observed micrographs (Figure 4), especially for shorter time intervals, where a significant allotriomorphic ferrite fraction is observed.

The TRIP780 steel submitted to step at $700^{\circ} \mathrm{C}$ for extremely short time presented a mostly martensitic microstructure and, at this condition, the highest hardness value was reached $\left(H V_{\text {máx }}\right)$. Increasing the step time and, as well as the ferrite fraction, the hardness values decreased reaching a minimum value $\left(H V_{\text {min }}\right)$ when the maximum ferrite fraction was formed. So, in the quasi-equilibrium situation, it can be considered that the instantaneous hardness $\left(H V_{t}\right)$ will tend to $H V_{\text {min }}$ In this scenario, using the lever rule, it can be written that $\frac{H V_{\text {máx }}-H V_{t}}{H V_{\text {máx }}-H V_{\text {min }}}=1$, that is, the maximum SF is obtained. Thus, the classic JMAK equation could be adapted to the form presented in Equation 5. So, it was possible to fit the JMAK equation to the SF data and to determine the kinetic constants $k$ and $n$.

$$
S F=1-\exp \left(-k t^{n}\right)
$$

Fitting Equation 5 to the experimental data, the Avrami exponent $(n)$ was determined as $1.5 \pm 0.4$ and the kinetic temperature-dependent constant $(k)$ as $(6 \pm 8) \times 10^{-3}$. The correlation coefficient was $R^{2}=0.94$, as shown in Figure 6-B. This shows that the kinetics of the SF, in the SQ heat treatments with step at $700^{\circ} \mathrm{C}$, also follows the JMAK model for TRIP780 steel.

It is noteworthy that both in the equation that predicts the kinetics of ferrite fraction, and in the equation that predicts the kinetics of the SF, the obtained kinetic constants were very similar, showing that the SF methodology to study and to predict the kinetics of ferrite formation is efficient for the studied steel. This result is very important, since measuring 

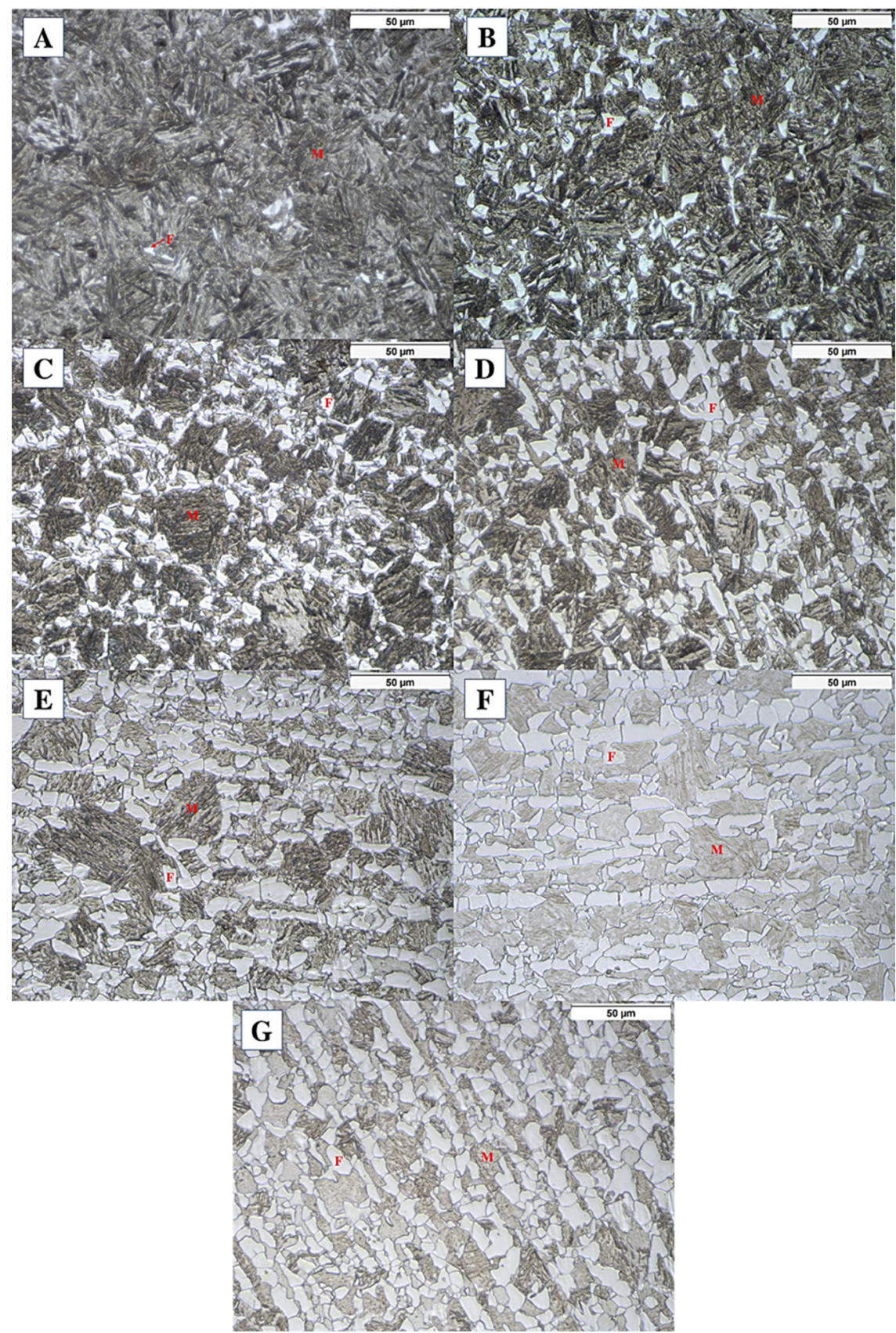

Figure 4. TRIP780 steel microstructures specimens submitted to SQ with a step temperature of $700^{\circ} \mathrm{C}$. step times: A) $5 \mathrm{~s}$; B) $10 \mathrm{~s}$; C) $15 \mathrm{~s}$; D) $30 \mathrm{~s}$; E) 60s; F) 600s; G) 1200s: F: ferrite; M: martensite - OM-500x - 4\% Nital etching.

hardness is a simpler and faster procedure when compared to performing phase fraction measurements, representing a relevant practical impact.

\subsection{Ferritic grain size}

The ferrite formation is a nucleation and growth diffusional process, which occurs with preferential nucleation in the austenitic grain boundaries and the growth stage is controlled by the carbon diffusion rate in ferrite-austenite interface. Thus, ferritic grain growth obeys Zener's law ${ }^{24}$, already presented in Equation 3.
In the studied steel subjected to SQ isotherm at $700^{\circ} \mathrm{C}$, the ferritic grain size had an accelerated growth at an early stage, obeying Zener's law (Figure 7-A). At a secondary stage, between the step times of $60 \mathrm{~s}$ and $1200 \mathrm{~s}$, there was a large slowdown in growth and the ferritic grain size approached a quasi-equilibrium configuration. Ashrafi et al. ${ }^{14}$, showed a similar effect for a DP steel, noting that after 100 seconds, for three evaluated step temperatures $\left(720^{\circ} \mathrm{C}, 750^{\circ} \mathrm{C}\right.$ and $\left.780^{\circ} \mathrm{C}\right)$, grain growth has a sharp deceleration, reaching a quasi-equilibrium condition.

Considering the grain size data of the specimens submitted to the step at $700^{\circ} \mathrm{C}$, it was possible to fit the 


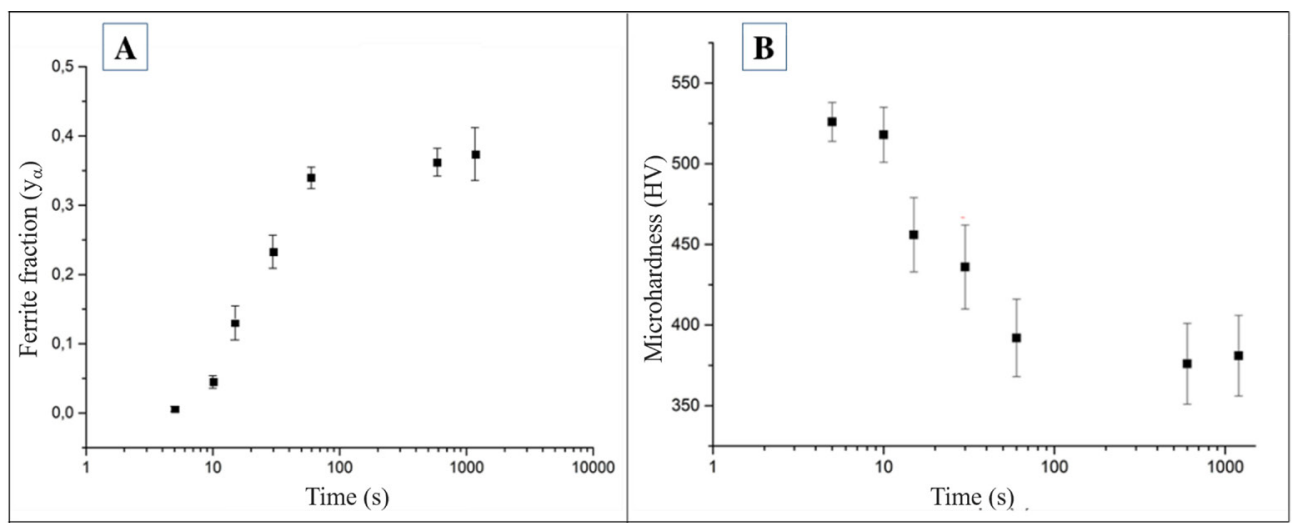

Figure 5. A) Ferrite fraction $\left(\mathrm{y}_{\alpha}\right)$ as a step time function and B) Vickers microhardness as a step time function. Isotherm: $700^{\circ} \mathrm{C}$.

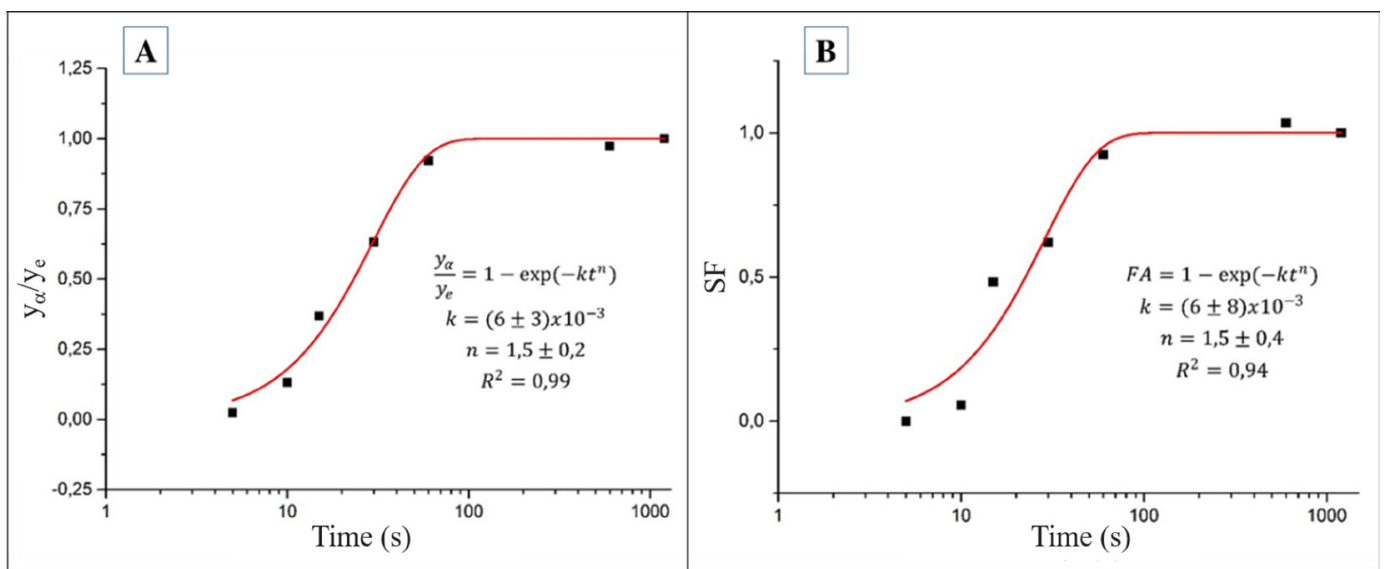

Figure 6. Fitting of JMAK model to the data obtained from: A) ferritic phase fraction as a time function; B) Vickers microhardness as a time function. Step at $700^{\circ} \mathrm{C}$.

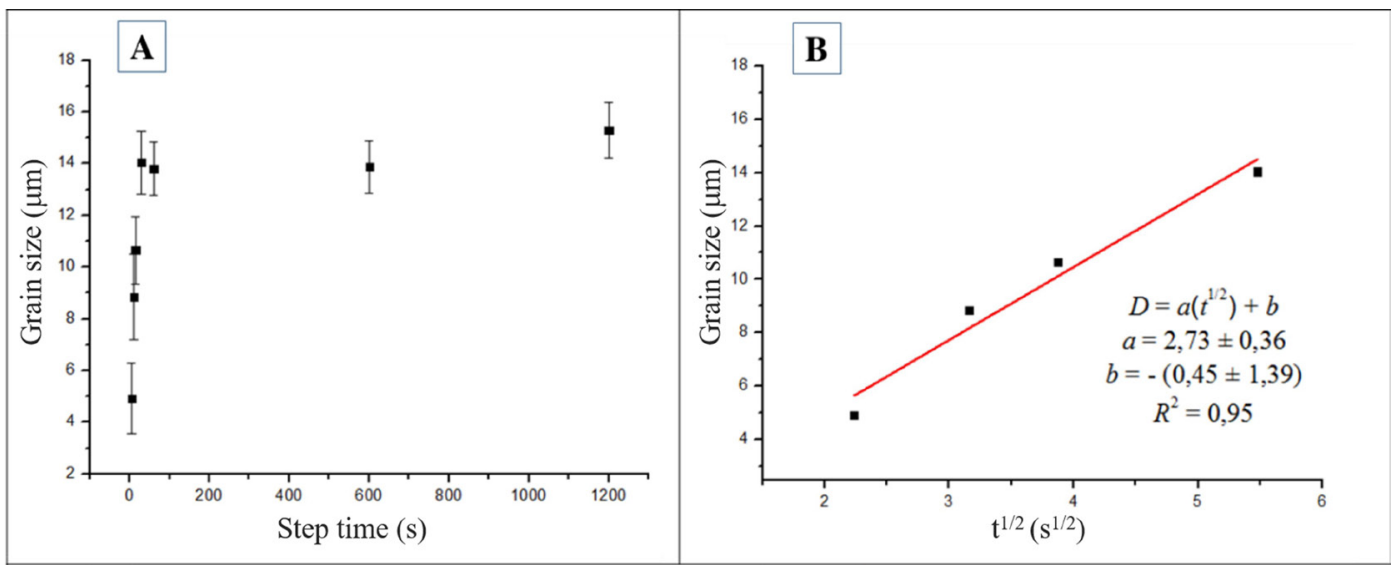

Figure 7. A) Grain size of polygonal ferrite as a step time function; B) Fitting of Zener equation to the first stage of ferrite grain growth. Step temperature: $700^{\circ} \mathrm{C}$.

Zener equation ${ }^{24}$ to the first stage of ferritic grain growth, that is, in the time interval between $5 \mathrm{~s}$ and $60 \mathrm{~s}$. Figure 7-B presents the obtained result. It was verified that for $700^{\circ} \mathrm{C}$, with a correlation coefficient of 0.95 , the constant $\alpha$ was determined as $2.72 \pm 0.36$. Ashrafi et al. ${ }^{14}$, studying the ferritic grain growth at $720^{\circ} \mathrm{C}$ for a DP steel, found 1.6, indicating a slower ferritic grain growth kinetic than that observed for TRIP780 steel at $700^{\circ} \mathrm{C}$.

Finally, considering the $700^{\circ} \mathrm{C}$ step temperature applied to the TRIP780 steel, it can be affirmed that the three evaluated 
variables (Vickers microhardness, ferrite fraction and ferritic grain size), after 60 s, tend to stabilize according to adapted JMAK equations. Ashrafi et al. ${ }^{14}$ also showed a similar behavior for a DP steel, where they highlighted that, after 100 s the stabilization trend of these three variables began.

\subsection{Martensite start temperature}

An important factor to be considered for the understanding and execution of the thermodynamic simulations is the $M_{s}$ temperature. For each specimen subjected to different time intervals at $700^{\circ} \mathrm{C}(\mathrm{SQ})$, the $\mathrm{M}_{\mathrm{s}}$ temperature was determined in the dilatometric curve using the minimum deviation method $^{31}$. Table 4 presents the obtained results.

A significant decrease in $\mathrm{M}_{\mathrm{s}}$ temperature was observed as the step time increased. One factor that strongly influences this temperature is the austenite carbon content $\mathrm{t}^{34,35}$, so that the higher the austenite carbon content, the lower its $M_{s}$ temperature. Thus, the decrease in $\mathrm{M}_{\mathrm{s}}$ temperature with the increase of step time, indicates the occurrence of carbon partition for austenite due to ferrite formation in the step stage. According to previous studies ${ }^{6,36-38}$, this partition can contribute significantly to the increase of retained austenite fraction at room temperature after the application of Q\&P cycles. However, the carbon partition for austenite due to the ferrite formation in an intercritical annealing, can lead to a non-homogeneous austenite carbon profile, as discussed by Tan et al. ${ }^{6}$ and Santofimia et al. ${ }^{36}$, influencing the retained austenite morphology and the occurrence of the TRIP effect during deformation ${ }^{39}$. The $\mathrm{M}_{\mathrm{s}}$ temperature determination after the SQ treatment is necessary to guarantee great agreement between the thermodynamic predictions and the real Q\&P heat treatments, since this $M_{s}$ value can be considered an indirect measurement of the austenite carbon content prior to the partial quenching in a Q\&P cycle ${ }^{35}$.

\subsection{Thermodynamic simulations of $S Q-Q \& P$ heat treatments}

A Q\&P heat cycle basically consists of a steel reheating for microstructure austenitizing (fully or partially), followed by a partial quenching to a QT temperature, between $M_{s}$ and $\mathrm{M}_{\mathrm{f}}$ and, finally, a partitioning step at QT temperature or slightly higher than this ${ }^{40}$. To maximize the retained austenite fraction obtained at the end of a Q\&P cycle, the CCE (constrained carbon equilibrium) model, initially proposed by Speer et al. ${ }^{2,17}$, starting from a microstructure formed by primary martensite and untransformed austenite fraction, proposes a constricted carbon balance, disregarding the mobility of iron atoms, the substitutional elements diffusion, and the interface mobility. Competitive reactions such as carbide precipitation and austenite into bainite decomposition are also considered to be completely suppressed. Then, the carbon partition, after the partial quenching, will end when the carbon chemical potential in the interfaces is equal in both phases (martensite and austenite). From these conditions, according to Speer et al. ${ }^{17}$, the retained austenite fraction in the final microstructure can be determined by the resolution of a system of equations allied to the Koistinen-Marburger equation $(\mathrm{K}-\mathrm{M})^{41}$.

From the CCE model, Li et al. ${ }^{25}$ proposed an alternative one for low carbon steels with $\mathrm{Si}$ and Mn additions, but now considering the possible occurrence of isothermal bainite formation during the partitioning stage. The model, named CCET, considers that the carbon partition from martensite to austenite is completed in the first seconds of the partitioning step, with the CCE model being applicable until that moment. After the initial seconds, for temperatures around $400^{\circ} \mathrm{C}$, as observed by the authors ${ }^{25}$, austenite can partially decompose into bainite (which is disregarded by the CCE model). In this context, the bainitic transformation can be modeled from the $\mathrm{T}_{0}$ curve $^{42}$, and can be used to predict the retained austenite fraction at the process end. For quenching and partitioning conditions in which isothermal bainite formation occurs from the untransformed austenite, the CCET model, unlike the CCE model, was optimally applied according to the Li et al. ${ }^{25}$ experimental data. Finally, both the CCE and CCET model can predict an optimal end quenching temperature (QT) used in partial quenching, where the highest retained austenite fraction in the final microstructure can be obtained.

In this study, in order to efficiently combine the SQ concept with Q\&P, some modifications were considered in the mentioned models, since, during an SQ treatment, a certain ferrite fraction will be formed. Therefore, an initial microstructure consisting of ferrite and austenite will be heat treated in the first step of Q\&P cycle, i.e. quenching. Equation 6 originates from a simplified relationship ${ }^{17,43}$ between the Henrian activity coefficients for carbon in ferrite and austenite, and it is considered that, at the partitioning stage end, martensite will have a very low carbon content (due to the carbon diffusion to austenite) similar to that of ferrite. Thus, in this work, for mathematical calculations, both ferrite and martensite are considered to be a single phase $\alpha$ (BCC phase).

Equation 6 relates the carbon chemical potentials of the $\alpha$ (ferrite and martensite) and $\gamma$ (austenite) phases through the carbon molar concentrations in the phases and absolute temperature, where, $X_{C}^{\gamma}, X_{C}^{\alpha}, R$ and $T$, are, respectively, the molar carbon concentration in $\gamma$, the molar carbon concentration in $\alpha$, the gases universal constant, and the absolute temperature. It is considered, as already mentioned, that the carbon partition ends when the carbon chemical potentials become equal in both phases, and this condition is reached during the partitioning stage. Therefore, the molar fractions present in Equation 6 correspond to those found at the partitioning stage end, with $T$ being equal to the partitioning temperature (PT).

Since the total carbon amount in the alloy does not vary, a solution can be found for Equation 6 using the Equation 7 , where $f_{C C E}^{\alpha}, f_{C C E}^{\alpha}, f_{C C E}^{\gamma}$, and $X_{C}^{\text {alloy }}$, represent,

Table 4. Effect of step time intervals at $700^{\circ} \mathrm{C}$ on the steel $\mathrm{M}_{\mathrm{s}}$ temperatures.

\begin{tabular}{cccccccc}
\hline Step time at $700^{\circ} \mathrm{C}(\mathrm{s})$ & 5 & 10 & 15 & 30 & 60 & 600 & 1200 \\
\hline $\mathrm{M}_{\mathrm{s}}$ temperature $\left({ }^{\circ} \mathrm{C}\right)$ & 365 & 359 & 362 & 347 & 310 & 265 & 264 \\
\hline
\end{tabular}


respectively, the volumetric ferrite \& martensite (formed in partial quenching) fraction, the volumetric untransformed austenite fraction (after partial quenching), and the alloy molar carbon concentration.

Equation 8 presents the K-M relation, which $f^{\alpha^{\prime}}$ represents the martensite fraction formed in QT, and $\mathrm{M}_{\mathrm{s}}$ is the martensite start temperature of austenite prior to partial quenching $\left(\mathrm{M}_{\mathrm{s}}\right.$ temperatures measured by dilatometry, i.e. data presented in Table 4).

Solving the equation system formed by Equation 6, Equation 7 and Equation 8, the martensite and austenite carbon concentrations are known after the end of carbon diffusion during the partitioning stage. Therefore, carbon enriched austenite has, at the partitioning end, a lower $M_{s}$ temperature (to be mathematically determined by empirical equations available in technical literature ${ }^{35}$ ). Thus, the final quenching up to room temperature can lead to the formation of a certain secondary martensite fraction, and can also be calculated by Equation 8 . Knowing that the sum of phase fractions should always be equal to 1 , and that the other constituents formation was not considered by the CCE model, the final microstructure will be formed only by ferrite (originating from the SQ), austenite, and martensite (primary and secondary). So, the retained austenite fraction in the microstructure at the Q\&P process end, becomes known by Equation 9, according to the CCE model. The final retained austenite and secondary martensite fractions are represented, respectively, by $f_{C C E}^{\gamma R A}$ and $f_{C C E}^{a "}$. Finally, the QT temperature can then be optimized for a value where the maximum retained austenite fraction is obtained.

$X_{C}^{\gamma}=X_{C}^{\alpha} \cdot e^{\frac{76789-43,8 T-(169105-120,4 T) X_{C}^{\gamma}}{R T}}$

$f_{C C E}^{\alpha} X_{C}^{\alpha}+f_{C C E}^{\gamma} X_{C}^{\gamma}=X_{C}^{\text {alloy }}$

$f^{\alpha^{\prime}}=1-e^{-0,011\left(M_{s}-Q T\right)}$

$f_{C C E}^{\gamma R A}+f_{C C E}^{\alpha "}=f_{C C E}^{\gamma}$

On the other hand, once the $\alpha$ and $\gamma$ phase fractions and carbon concentrations in the first partitioning seconds are known by CCE model, the CCET model proposes some equations (Equation 10, Equation 11, and Equation 12) to determine the bainite and retained austenite fractions at the end of the Q\&P process. The austenite, bainite and $\alpha$ volumetric phase fractions, at the end of partitioning, are represented, respectively, by $f_{C C E T}^{\gamma}, f_{B}, f_{C C E}^{\alpha}$ ( $\alpha$ fraction obtained in the CCE model). The carbon concentrations (wt.\%) of alloy, austenite (determined by the $\mathrm{T}_{0}$ curve), bainite (considered to be equal to $0.03 \%{ }^{42}$ ), and $\alpha$ (determined by the CCE model) are represented, respectively, by $X_{C}^{\text {alloy }}, C_{\gamma}, C_{B}$ e $X_{C}^{\alpha}$ . The retained austenite fraction at the process end, that is, after the second quenching, is given by $f_{C C E T}^{\gamma R A}$, with $f_{C C E T}^{\alpha "}$ being the secondary martensite fraction.

$$
f_{C C E T}^{\gamma} C_{\gamma}+f_{B} C_{B}+f_{C C E}^{\alpha} X_{C}^{\alpha}=X_{C}^{\text {alloy }}
$$

$$
f_{C C E T}^{\gamma}+f_{B}+f_{C C E}^{\alpha}=1
$$

$$
f_{C C E T}^{\gamma R A}+f_{C C E T}^{\alpha "}=f_{C C E T}^{\gamma}
$$

As proposed by the CCE model, the CCET model can also predict an optimal QT temperature for which the highest retained austenite fraction is expected.

Chen et al. ${ }^{44}$, studying a $0.2 \mathrm{C}-2.82 \mathrm{Mn}-1.58 \mathrm{Si}$ steel, showed that the occurrence of bainitic transformation in the Q\&P process leads to a greater retained austenite fraction due to the optimization of carbon redistribution (which increase the austenite stability) in addition to carbon partition during the transformation ${ }^{45}$. This lead to a significant improvement in uniform and total elongation combined with a high strength, with which other authors also agree ${ }^{46-49}$. Li et al. ${ }^{25}$, as already mentioned, proposed the CCET model precisely based on the bainitic transformation occurrence in C-Mn-Si steels submitted to Q\&P processes, with partitioning temperatures between $350^{\circ} \mathrm{C}$ and $450^{\circ} \mathrm{C}$. This temperature range accelerates the kinetics of bainitic formation in this steel class ${ }^{32}$, combined with the fact that, according to Kawata et al..$^{50}$, the martensite pre-existence from partial quenching also favors bainitic transformation, i.e. during the partitioning stage in a Q\&P cycle. According to Dai et al. ${ }^{4}$, in the temperature range from $350^{\circ} \mathrm{C}$ to $430^{\circ} \mathrm{C}$, the transition carbides and cementite formation may occur, which should be suppressed by the presence of $\mathrm{Si}$, but only once the partitioning time is optimized. Therefore, the typical partition temperature in $\mathrm{Q} \& \mathrm{P}$ processes that consider bainitic transformation as beneficial to Q\&P steels is $400^{\circ} \mathrm{C}^{4}$. Hence, the partition temperature used for thermodynamic simulations in this work was $400^{\circ} \mathrm{C}$.

Figure 8 shows the retained austenite final fraction (RA) curves versus partial quenching temperature (QT) for different conditions, according to the CCE and CCET models. Before the simulation of the Q\&P cycles, it was considered that the initial microstructure was the one obtained in the SQ heat treatments at $700^{\circ} \mathrm{C}$, applying different step times (5s, 10s, 15s, 30s, 60s, 600s, and 1200s). Therefore, the initial microstructure was considered biphasic, constituted of ferrite and austenite. After the Q\&P simulations, the final microstructures, according to the thermodynamic models, could consist of ferrite, primary and secondary martensite, retained austenite, and bainite, with bainite being considered only in the CCET model.

The maximum retained austenite fraction predicted in both models for the composition of the studied commercial TRIP780 steel was approximately $20 \%$, regardless of the initial condition (step time). This is explained by the fact that the CCE model considers a carbon chemical potential balance between the phases $\alpha$ and $\gamma$, and, by changing the ferrite fraction (within the values range obtained in this work), the maximum retained austenite final fraction at the optimum 


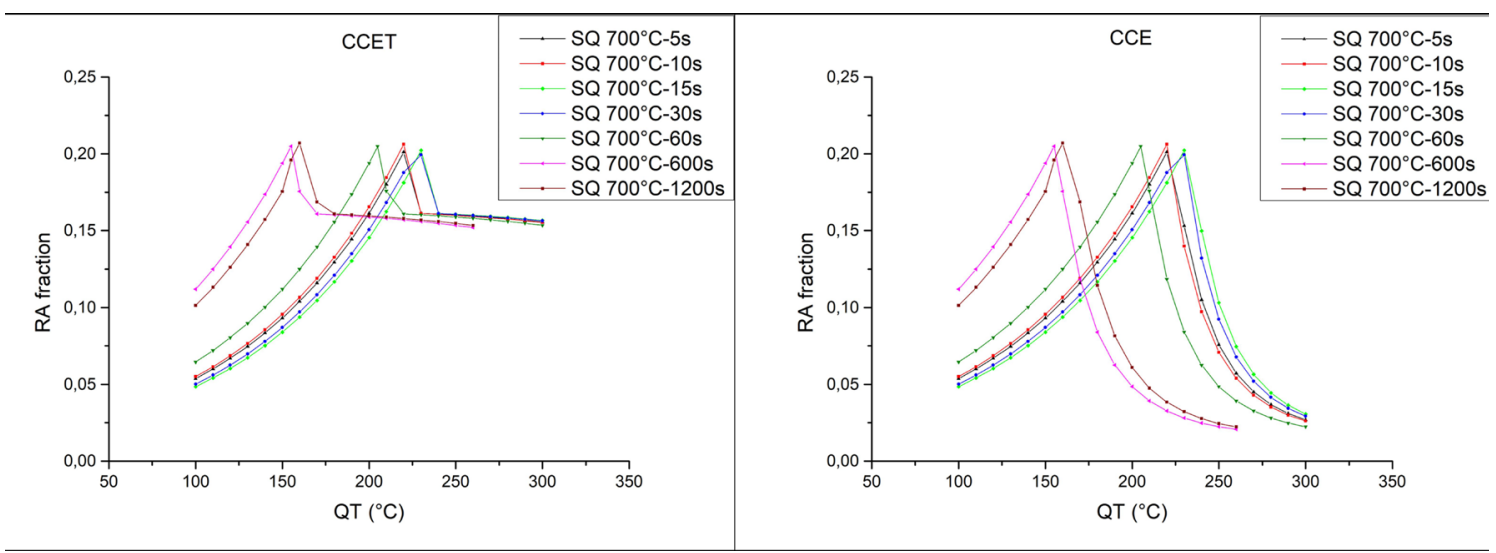

Figure 8. Partial quenching temperature $(\mathrm{QT})$ as a retained austenite final fraction function predicted by the thermodynamic models CCE and CCET from the application of Q\&P cycles in microstructures previously treated in different SQ cycles. Partitioning temperature equal to $400^{\circ} \mathrm{C}$.

QT temperature is not altered. However, the higher the ferrite amount in the microstructure after SQ treatment, the lower QT should be for the formation of an ideal martensite fraction to obtain the maximum retained austenite fraction. Thus, considering the ferrite fraction in the SQ varying between approximately $0 \%$ and $40 \%$, the optimum QT temperature ranged from $230^{\circ} \mathrm{C}$ to approximately $150^{\circ} \mathrm{C}$, respectively.

This result emphasizes the importance of precise control of QT temperature as a function of the microstructure prior to partial quenching, aiming to reach the highest final fraction of retained austenite. As can be observed in the curves presented in Figure 8, for the same SQ condition, comparing the CCE and CCET models, the retained austenite fractions are identical for QT values that are lower than the optimal QT. This is due to the fact that the two models are mathematically equal if the applied QT value is lower than the optimal QT, once, according to the CCET model, bainite has not yet formed in the partitioning stage from the untransformed austenite. This occurs because at relatively low QT temperatures high fractions of primary martensite are formed, leading to small amount of bainite transforming. However, at higher QT temperatures, with lower content of primary martensite, the austenite to bainite isothermal transformation is favored.

For temperatures above the optimal QT, by the CCET model, part of the unprocessed austenite will be decomposed into carbide free bainite, and then the retained austenite fraction is decreased (in relation to the fraction in the optimum QT) and, at the same time, carbon enriched. According to the CCET model, carbon enrichment due to bainitic transformation allows the stability of a given retained austenite fraction even for a high QT, unlike the prediction of the CCE model. Li et al. ${ }^{25}$ showed that the CCET model can be used as a good predictor of the RA fraction using partitioning temperatures of around $400^{\circ} \mathrm{C}$ (temperature range where the CCE model did not serve as a good predictor) for alloys with typical TRIP steels chemical composition.

The CCE model showed that, for temperatures below the optimal QT, the primary martensite fraction increases, and all untransformed austenite in the first quenching will be retained, with no secondary martensite formation occurring in the final quenching. This is different from what occurs for a quenching temperature higher than the optimal $\mathrm{QT}^{51}$. This is explained by the fact that the carbon source considered for stabilization of untransformed austenite in the first quenching is the primary martensite, and a certain amount of martensite is necessary for austenite to be stabilized at room temperature, while also considering a carbon mass balance between the phases $^{52}$. The CCET model predicts different phase fractions when the quenching temperature is higher than the optimum QT temperature. This happens because the partial austenite into carbide-free bainite decomposition with simultaneous carbon rejection for austenite is considered, thus predicting a higher retained austenite final fraction (in relation to the CCE model), and a lower secondary martensite fraction ${ }^{25}$. The appropriate heat cycle choice will depend on the desired mechanical properties, and the technical feasibility for the heat treatments application ${ }^{53}$

During tensile tests on a TRIP steel $(0.18 \mathrm{C}-0.53 \mathrm{Si}-1.95 \mathrm{Mn}-$ 1.46Al-0.08P), Tan et al. ${ }^{6}$ observed a preferential softer phase deformation (ferrite formed during an SQ treatment), which may contribute to the cracks formation between the different phases in the microstructure. At the same time, according to the authors, the presence of ferrite in the microstructure increases the material ductility, due to a higher work hardening in this phase, and this favors the mechanical partition for the retained austenite. Thus, the gradient of deformation between the highest and lowest strength phases is decreased if ferrite work hardening is considered. Therefore, through the contribution of ferrite work hardening and the TRIP effect, in a properly optimized microstructure, the crack initiation can be delayed. Finally, they concluded that for TRIP effect optimization in multiphase steels, the mechanical partition between the phases present in the microstructure should be considered (in addition to the fraction, carbon content, retained austenite morphology, size and crystallography). Then, there is the possibility of combining SQ (a technique already applied to the automotive steels' production) and Q\&P treatments to obtain an optimized microstructure in terms of mechanical properties. Thus, nowadays the automotive industry has great interest in-depth studies to optimize SQ cycles combined with Q\&P, obtaining optimal parameters 


\section{SQ-Q\&P cycle}

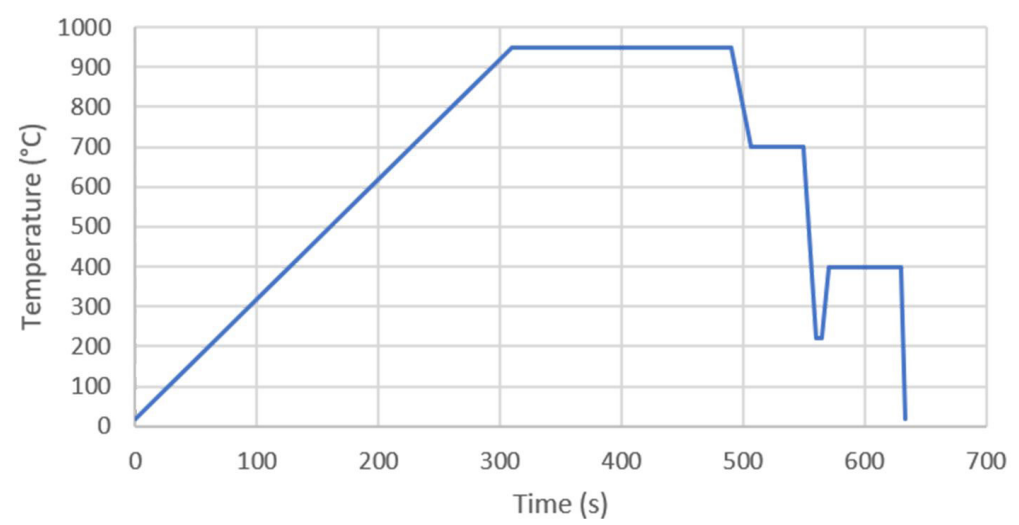

Figure 9. Schematic SQ heat cycle design followed by Q\&P process.

Table 5. Final phase fractions predicted by the CCE and CCET models after the combination of SQ and Q\&P cycles, with different Step times and QT temperatures. $f^{\gamma R A}, f^{a^{\prime}}, f^{a "}, f^{a}$ and $f^{B}$ represent, respectively, the retained austenite, primary martensite, secondary martensite, ferrite and bainite fractions, according to the CCE or CCET models (as signed).

\begin{tabular}{|c|c|c|c|c|c|c|c|c|c|c|}
\hline $\begin{array}{c}\text { SQ } \\
\text { condition }\end{array}$ & $\mathrm{QT}\left({ }^{\circ} \mathrm{C}\right)$ & PT $\left({ }^{\circ} \mathrm{C}\right)$ & $f_{C C E}^{\gamma R A}$ & $f_{C C E}^{a^{\prime}}$ & $f_{C C E}^{a^{\prime \prime}}$ & $f^{a}$ & $f_{C C E T}^{\gamma R A}$ & $f_{C C E T}^{B}$ & $f_{C C E T}^{a^{\prime}}$ & $f_{C C E T}^{a^{\prime \prime}}$ \\
\hline \multirow{3}{*}{$\begin{array}{c}700^{\circ} \mathrm{C} \\
30 \mathrm{~s}\end{array}$} & 180 & \multirow{6}{*}{400} & 0.12 & 0.64 & 0 & \multirow{3}{*}{0.24} & 0.12 & 0 & 0.64 & 0 \\
\hline & 230 & & 0.20 & 0.55 & 0.01 & & 0.20 & 0 & 0.55 & 0.01 \\
\hline & 280 & & 0.04 & 0.40 & 0.32 & & 0.16 & 0.14 & 0.40 & 0.06 \\
\hline \multirow{3}{*}{$\begin{array}{c}700^{\circ} \mathrm{C} \\
60 \mathrm{~s}\end{array}$} & 180 & & 0.16 & 0.49 & 0 & \multirow{3}{*}{0.35} & 0.16 & 0 & 0.49 & 0 \\
\hline & 205 & & 0.20 & 0.45 & 0 & & 0.20 & 0 & 0.45 & 0 \\
\hline & 230 & & 0.08 & 0.38 & 0.19 & & 0.16 & 0.05 & 0.38 & 0.06 \\
\hline
\end{tabular}

for the execution of heat treatments, as is the case of QT temperature optimization.

Hence, considering the studied steel, in practical terms, there is a great potential to reach an interesting multiphasic microstructure and balanced mechanical properties by applying a SQ heat treatment at $700^{\circ} \mathrm{C}$ (for 30s - 60s) followed by a Q\&P process with quenching temperature close to the optimum QT temperature and partitioning at $400^{\circ} \mathrm{C}$. Thus, a ferrite fraction between $25 \%$ and $35 \%$ would be obtained, ensuring a good ductility to the final microstructure ${ }^{54}$ as well as a high strength due to the presence of a considerable martensite, retained austenite, and carbide-free bainite fractions. Figure 9 presents a schematic illustration of this possible heat treatment combination. The phase final fractions, for different heat cycles, predicted by the CCE and CCET models, are shown in Table 5. It is important to highlight that: these heat cycles are optimized conditions based on the physical and thermodynamic simulations performed in this work; the kinetic characterization of ferrite formation at the step temperature and the $\mathrm{M}_{\mathrm{s}}$ temperature determination as a function of the SQ heat treatment are essential input data for the simulation. Thus, SQ-Q\&P cycles could be simulated, reaching optimal conditions in the context of this study.

\section{Conclusions}

Considering the conditions evaluated in this study, it was observed that the increase in the austenite supercooling degree (decrease in step temperature) favored the kinetics of primary ferrite formation during the isothermal heat treatment, being the kinetics satisfactorily modeled by the JMAK equation. The SF also follows the JMAK model, and the SF methodology for studying and predicting the kinetics of ferrite formation is efficient for the studied steel. This result is very important, since measuring hardness is a simpler and faster procedure when compared to performing phase fraction measurements, representing a relevant practical impact.

The kinetics of ferritic grain growth for the TRIP780 steel at the step temperature of $700^{\circ} \mathrm{C}$ takes place in two stages. At an early stage, it obeys Zener's law. At a secondary stage, there is a notable slowdown in ferritic grain growth that approaches quasi-equilibrium configuration.

For all variables studied at the $700^{\circ} \mathrm{C}$ step temperature, there was a stabilization trend after 60 s of step isotherm. This shows that, after a certain time interval, the variation of these parameters is very small, whilst approaching quasiequilibrium as step time is increased.

The thermodynamic modeling of SQ-Q\&P cycles showed that this combination can provide a high retained austenite fraction in a multiphase microstructure containing ferrite, martensite and carbide-free bainite. As a result, a SQ heat treatment followed by the Q\&P cycle has the potential to generate a steel consisting of a high strength and of a good deformation capacity, which also achieves the ultimate objective of a final microstructure assisted by the TRIP effect. 
At the same time, as the SQ process is already executed industrially, the feasibility of applying Q\&P heat treatments combined with SQ can be facilitated.

\section{Acknowledgements}

The authors would like to thank the Conselho Nacional de Desenvolvimento Científico e Tecnológico (CNPq) for the financial support.

\section{References}

1. Keeler S, Kimchi MJ, Mooney P. Advanced high-strength steels apllication guidelines version 6.0. Brussels: World Steel Association; 2017. 314 p.

2. Matlock DK, Bräutigam VE, Speer JG. Application of the quenching and partitioning (Q\&P) process to a mediumcarbon, high-Si microalloyed bar steel. Mater Sci Forum. 2003;426(432):1089-94.

3. Aydin H, Essadiqi E, Jung IH, Yue S. Development of 3rd generation AHSS with medium Mn content alloying compositions. Mater Sci Eng A. 2013;564:501-8.

4. Dai Z, Chen H, Ding R, Lu Q, Zhang C, Yang Z, et al. Fundamentals and application of solid-state phase transformations for advanced high strength steels containing metastable retained austenite. Mater Sci Eng Rep. 2021;143:100590.

5. Liu Q, Tang D, Jiang HT, Liu RD, Tang XY. Research and development of $780 \mathrm{MPa}$ cold rolling TRIP-aided steel. Int J Miner Metall Mater. 2009;16(4):399-406.

6. Tan X, Ponge D, Lu W, Xu Y, He H, Yan J, et al. Joint investigation of strain partitioning and chemical partitioning in ferritecontaining TRIP-assisted steels. Acta Mater. 2020;186:374-88.

7. De Cooman BC. Structure-properties relationship in TRIP steels containing carbide-free bainite. Curr Opin Solid State Mater Sci. 2004;8(3-4):285-303.

8. Park KS, Park KT, Lee DL, Lee CS. Effect of heat treatment path on the cold formability of drawn dual-phase steels. Mater Sci Eng A. 2007;448-451:1135-8.

9. Li X, Shi L, Liu Y, Gan K, Liu C. Achieving a desirable combination of mechanical properties in HSLA steel through step quenching. Mater Sci Eng A. 2020;772:138683.

10. Liu Y, Shi L, Liu C, Yu L, Yan Z, Li H. Effect of step quenching on microstructures and mechanical properties of HSLA steel. Mater Sci Eng A. 2016;675:371-8.

11. Magalhães CHXM, Mourão GMM, Campos PHK, Faria GL. Caracterização das transformaçoes de fases sob resfriamento contínuo de um aço do tipo TRIP780. In: ABM Proceedings; 2019; São Paulo. São Paulo: ABM; 2019. p. 203-14.

12. Shao Y, Liu C, Yan Z, Li H, Liu Y. Formation mechanism and control methods of acicular ferrite in HSLA steels: a review. J Mater Sci Technol. 2018;34(5):737-44.

13. Miettunen I, Ghosh S, Somani MC, Pallaspuro S, Kömi J. Competitive mechanisms occurring during quenching and partitioning of three silicon variants of $0.4 \mathrm{wt} . \%$ carbon steels. J Mater Res Technol. 2021;11:1045-60.

14. Ashrafi H, Shamanian M, Emadi R, Saeidi N. Examination of phase transformation kinetics during step quenching of dual phase steels. Mater Chem Phys. 2017;187:203-17.

15. Guo W, Wan Z, Peng P, Jia Q, Zou G, Peng Y. Microstructure and mechanical properties of fiber laser welded QP980 steel. J Mater Process Technol. 2018;256(37):229-38.

16. Peng F, Xu Y, Li J, Gu X, Wang X. Interaction of martensite and bainite transformations and its dependence on quenching temperature in intercritical quenching and partitioning steels. Mater Des. 2019;181:107921.
17. Speer J, Matlock DK, De Cooman BC, Schroth JG. Carbon partitioning into austenite after martensite transformation. Acta Mater. 2003;51(9):2611-22.

18. Zhong N, Wang XD, Wang L, Rong YH. Enhancement of the mechanical properties of a Nb-microalloyed advanced highstrength steel treated by quenching-partitioning-tempering process. Mater Sci Eng A. 2009;506(1-2):111-6.

19. Wang F, Zhu Y, Zhou H, Jiang B, Wang G. A novel microstructural design and heat treatment technique based on gradient control of carbon partitioning between austenite and martensite for high strength steels. Sci China Technol Sci. 2013;56(8):1847-57.

20. Cai HL, Chen P, Oh JK, Cho YR, Wu D, Yi HL. Quenching and flash-partitioning enables austenite stabilization during press-hardening processing. Scr Mater. 2020;178:77-81.

21. Hou ZR, Opitz T, Xiong XC, Zhao XM, Yi HL. Bake-partitioning in a press-hardening steel. Scr Mater. 2019;162:492-6.

22. Kantanen PK, Javaheri V, Somani MC, Porter DA, Kömi JI. Effect of deformation and grain size on austenite decomposition during quenching and partitioning of (high) siliconaluminum steels. Mater Charact. 2020;171:110793.

23. Dai Z, Yang Z, Zhang C, Chen H. Incomplete carbon partitioning during quenching and partitioning of $\mathrm{Fe}-\mathrm{C}-\mathrm{Mn}-\mathrm{Si}$ steels: modeling and experimental validations. Acta Mater. 2020;200:597-607.

24. Zener C. Theory of growth of spherical precipitates from solid solution. J Appl Phys. 1949;20(10):950-3.

25. Li Y, Chen S, Wang C, Martín DS, Xu W. Modeling retained austenite in Q\&P steels accounting for the bainitic transformation and correction of its mismatch on optimal conditions. Acta Mater. 2020;188:528-38.

26. ASTM: American Society for Testing and Materials. ASTM E3-01:standard practice for preparation of metallographic specimens. West Conshohocken: ASTM Internacional; 2001.

27. ASTM: American Society for Testing and Materials. ASTM E1245-03: standard practice for determining the inclusion or second-phase constituent content of metals by automatic image analysis. West Conshohocken: ASTM Internacional; 2003.

28. ASTM: American Society for Testing and Materials. ASTM E112-13: standard test methods for determining average grain size. West Conshohocken: ASTM Internacional; 2013.

29. Alekseechkin NV. Extension of the Kolmogorov-Johnson-MehlAvrami theory to growth laws of diffusion type. J Non-Cryst Solids. 2011;357(16-17):3159-67.

30. Kooi BJ. Extension of the Johnson-Mehl-Avrami-Kolmogorov theory incorporating anisotropic growth studied by Monte Carlo simulations. Phys Rev B Condens Matter Mater Phys. 2006;73(5):054103.

31. De Andrés CG, Caballero FG, Capdevila C, Álvarez LF. Application of dilatometric analysis to the study of solid-solid phase transformations in steels. Mater Charact. 2002;48(1):10111.

32. Bhadeshia HKDH. Bainite in steels. 2nd ed. London: IOM Communications Ltd.; 2001. 454 p.

33. Porter DA, Easterling KE, Sherif MY. Phase transformations in metals and alloys. 3rd ed. Boca Raton: CRC Press; 2009. $521 \mathrm{p}$.

34. Bhadeshia HKDH, Honeycombe RWK. Steels: microestructure and properties. 3rd ed. Oxford: Elsevier; 2006. 344 p.

35. Souza SS, Moreira PS, Faria GL. Austenitizing temperature and cooling rate effects on the martensitic transformation in a microalloyed-steel. Mater Res. 2020;23(1):1-9.

36. Santofimia MJ, Zhao L, Sietsma J. Microstructural evolution of a low-carbon steel during application of quenching and partitioning heat treatments after partial austenitization. Metall Mater Trans, A Phys Metall Mater Sci. 2009;40(1):46-57.

37. Yan S, Liu X, Liu WJ, Liang T, Zhang B, Liu L, et al. Comparative study on microstructure and mechanical properties of a C-Mn-Si steel treated by quenching and partitioning (Q\&P) processes 
after a full and intercritical austenitization. Mater Sci Eng A. 2017;684:261-9.

38. Kurup V, Siyasiya CW, Mostert RJ, Wicks J. The influence of full and partial austenitization temperatures on the quench and partition heat treatment process for an advanced high strength steel. IOP Conf Series Mater Sci Eng. 2018;430(1):012045.

39. Xiong XC, Chen B, Huang MX, Wang JF, Wang L. The effect of morphology on the stability of retained austenite in a quenched and partitioned steel. Scr Mater. 2013;68(5):321-4.

40. De Moor E, Speer JG. Bainitic and quenching and partitioning steels. In: Rana R, Singh SB, editors. Automotive steels: design, metallurgy, processing and applications. Amsterdam: Elsevier; 2017. p. 289-316.

41. Koistinen DP, Marburger RE. Ageneral equation prescribing the extent of the austenite-martensite transformation in pure iron-carbon alloys and plain carbon steels. Acta Metall. 1959;7(1):59-60.

42. Bhadeshia HKDH, Edmonds DV. Mechanism of bainite formation in steels. Acta Metall. 1980;28(9):1265-73.

43. Bhadeshia HKDH. Driving force for martensitic transformation in steels. Met Sci. 1981;15(4):175-7.

44. Chen S, Hu J, Shan L, Wang C, Zhao X, Xu W. Characteristics of bainitic transformation and its effects on the mechanical properties in quenching and partitioning steels. Mater Sci Eng A. $2021 ; 803: 140706$.

45. Kong H, Chao Q, Cai MH, Pavlina EJ, Rolfe B, Hodgson $\mathrm{PD}$, et al. Microstructure evolution and mechanical behavior of a CMnSiAl TRIP steel subjected to partial austenitization along with quenching and partitioning treatment. Metall Mater Trans, A Phys Metall Mater Sci. 2018;49(5):1509-19.

46. Gao G, Zhang H, Gui X, Luo P, Tan Z, Bai B. Enhanced ductility and toughness in an ultrahigh-strength $\mathrm{Mn}-\mathrm{Si}-\mathrm{Cr}-\mathrm{C}$ steel: the great potential of ultrafine filmy retained austenite. Acta Mater. 2014;76:425-33.

47. Gao G, Zhang H, Gui X, Tan Z, Bai B, Weng Y. Enhanced strain hardening capacity in a lean alloy steel treated by a "disturbed" bainitic austempering process. Acta Mater. 2015;101:31-9.

48. Huyghe P, Malet L, Caruso M, Georges C, Godet S. On the relationship between the multiphase microstructure and the mechanical properties of a $0.2 \mathrm{C}$ quenched and partitioned steel. Mater Sci Eng A. 2017;701:254-63.

49. An B, Zhang C, Gao G, Gui X, Tan Z, Misra RDK, et al. Experimental and theoretical analysis of multiphase microstructure in a newly designed $\mathrm{MnSiCrC}$ quenched and partitioned steel to promote bainitic transformation: the significant impact on mechanical properties. Mater Sci Eng A. 2019;757:117-23.

50. Kawata H, Hayashi K, Sugiura N, Yoshinaga N, Takahashi M. Effect of martensite in initial structure on bainite transformation. Mater Sci Forum. 2010;638-642:3307-12.

51. Speer JG, Rizzo Assunção FC, Matlock DK, Edmonds DV. The "quenching and partitioning" process: background and recent progress. Mater Res. 2005;8(4):417-23.

52. Clarke AJ, Speer JG, Matlock DK, Rizzo FC, Edmonds DV, Santofimia MJ. Influence of carbon partitioning kinetics on final austenite fraction during quenching and partitioning. Scr Mater. 2009;61(2):149-52.

53. Fonstein N. Advanced high strength sheet steels: physical metallurgy, design, processing, and properties. Cham: Springer; 2015. 396 p.

54. Ariza EA, Nishikawa AS, Goldenstein H, Tschiptschin AP. Characterization and methodology for calculating the mechanical properties of a TRIP-steel submitted to hot stamping and quenching and partitioning (Q\&P). Mater Sci Eng A. 2016;671:54-69. 